Baseline survey of animal trypanosomosis in the region of the Boucle du Mouhoun,

\title{
Burkina Faso
}

A. Sow ${ }^{1,2,3}$, R. Ganaba ${ }^{4}$, L. Percoma ${ }^{2}$, I. Sidibé ${ }^{1,2}$, Z. Bengaly ${ }^{1}$, Y. Adam ${ }^{5}$, P. Koné ${ }^{3}$, G. J. Sawadogo ${ }^{3}$, J. Van Den Abbeele ${ }^{6}$, T. Marcotty ${ }^{6,7}$, V. Delespaux ${ }^{6, *}$

${ }^{1 .}$ Centre International de Recherche-Développement sur l'Elevage en Zone subhumide, 01 BP. 454 Bobo-Dioulasso 01, Burkina Faso

2. Pan-African Tsetse and Trypanosomosis Eradication Campaign (PATTEC) / Projet de Création de Zones Libérées Durablement de Tsé-tsé et de Trypanosomoses (PCZLD), 01 BP. 1087 Bobo-Dioulasso 01, Burkina Faso

3. Ecole Inter-Etats des Sciences et Médecine Vétérinaires (EISMV), BP. 5077 Dakar Fann, Sénégal

4. Agence de Formation, de Recherche et d'Expertise en Santé pour l'Afrique (AFRICSanté), 01 BP 298 Bobo-Dioulasso 01, Burkina Faso

5. Veterinary Services Department of MOFA, P.O. Box 97, Pong-Tamale, Ghana

6. Department of Biomedical Sciences -, Institute of Tropical Medicine, Nationalestraat 155, 2000 Antwerp, Belgium

7. University of Pretoria, Private Bag X04, Onderstepoort 0110, South Africa

*Corresponding author: Tel: +32-3-2476390 / fax: +32-3-2476268; E-mail: vdelespaux@itg.be. 


\section{Abstract}

In view of gathering baseline information about the prevalence of animal trypanosomosis, the Pan African Tsetse and Trypanosomiasis Eradication Campaign (PATTEC) funded a cross sectional survey in the Region of the Boucle du Mouhoun which constitutes the Northern limit of the tsetse distribution in Burkina. This cross sectional study was carried out in 53 villages located in the 6 provinces of the region. A total of 2002 cattle, 1466 small ruminants and 481 donkeys were sampled. This survey showed that about $25 \%$ of the cattle had been treated with trypanocidal drugs within 3 months before the survey compared to $3 \%$ and $0.42 \%$ for the small ruminants and donkeys respectively. Parasitological prevalence in cattle was low: $0.77 \%$ (95\% C.I. $0.30-1.95 \%)$. No goats and three donkeys were found infected with trypanosomes. Infections were mainly due to Trypanosoma vivax $(75.0 \%)$ with cases of $T$. congolense (25.0\%). In cattle, the serological prevalence of trypanosomosis, for the entire Region of the Boucle du Mouhoun, was 34.2\% (95\%C.I. 26.1-43.4\%). For sheep, goats and donkeys, the prevalence were of $20.9 \%$ (95\%C.I. 12.2-33.5\%), $8.5 \%$ (95\%C.I. 5.7-12.5\%) and 5.8\% (95\%C.I. 3.9-8.6\%) respectively.The age and distance to the river were the two main risk factors associated with seropositivity.

Key words: Boucle du Mouhoun, Burkina Faso, PATTEC, Trypanosomosis, Small ruminants, Donkeys 


\section{INTRODUCTION}

The economy of Burkina Faso is largely dependent on pastoral agriculture. The contribution of the national herds to the gross domestic product ranges from 10 to $14 \%$ (MEDEV,2002; MEDEV,2004). The livestock includes cattle (8 million), small ruminants (18 million), pigs (2 million) and equids (1 million) (Ministère des Ressources Animales,2010). Ruminants are either raised in sedentary or transhumant animal husbandry systems mostly on communal natural pastures and with limited access to adequate veterinary health care delivery. This system of livestock management highly exposes animals to the risk of disease outbreaks which are indeed often reported by the veterinary services (Ministère des Ressources Animales,2006; Ministère des Ressources Animales,2010). Among all the diseases, trypanosomosis being the most frequent one greatly hampers livestock productivity in Burkina Faso (Ministère des Ressources Animales,2006). One third of the total surface of the country is at risk of the disease. More than $63 \%$ of the country's cattle population is raised in zones with high trypanosomosis risk (Kamuanga et al., 2001). Those zones are partially preserved from human activities offering good grazing capacities for the cattle but, at the same time, providing suitable refuges for the tsetse flies.

In Burkina Faso, the financial costs of trypanocidal compounds have been estimated to be 3.9 million US\$ per annum (Sow et al., 2010). Treatments with trypanocidal drugs constitute the most frequently used method for controlling trypanosomosis and maintaining susceptible breeds in tsetse infested areas. However, extended use of these drugs led to the development of chemoresistance in all trypanosomosis enzootic areas of Burkina Faso (Clausen et al., 1992; McDermott et al., 2003; Talaki et al., 2007; Sow et al., 2012). 
The Government of Burkina Faso tried to mitigate the impact of human and animal trypanosomosis with the support of international partners. All previous efforts to eliminate tsetse and trypanosomosis in the country failed because of the interconnections between the different river systems within and outside the country and the lack of a concerted approach in dealing with this trans-boundary animal disease (Adam et al., 2012).

The Pan-African Tsetse and Trypanosomosis Eradication Campaign (PATTEC) is the most recent programme that was launched to eliminate tsetse and trypanosomosis. Thirty seven African countries endemic for human and animal trypanosomosis are participating to the campaign. In Burkina Faso, the Region of the Boucle du Mouhoun was selected as one of the initial locations for the implementation of the PATTEC initiative. Indeed, this region is located at the Northern limit of the tsetse distribution (Laveissière,1976; Hendrickx et al., 1999) and the subsequent elimination campaign will be carried out following the "rolling carpet" strategy from North to South. Preventing reinvasion of flies living in the adjacent river basins i.e. the Comoé, The Niger and the Sissili river basins would be indicated since the population of flies originating from the different water basins are genetically interconnected (Solano et al., 2010; Kone et al., 2011). The present survey was conducted before implementing the eradication campaign with the aim of determining the prevalence of trypanosome infections and the health status of farm animals by using the packed cell volume (PCV) and Body Condition Score (BCS) as indicators. A cross-sectional survey was conducted from September to December 2007, during the transition rainy to dry season (i) to identify hot spots (high prevalence of the disease) to conduct block treatment for trypanocidal drug resistance testing, (ii) to get an estimate of the disease prevalence, (iii) to 
assess the impact of the disease on the health status of the animals and indirectly (iv) to evaluate the efficiency of the treatments with trypanocidal drugs in the area.

\section{MATERIAL AND METHODS}

\section{Study area}

The Region of the Boucle du Mouhoun, is located at the North-West of Burkina Faso between $2^{\circ} 4^{\prime}-4.6^{\circ} \mathrm{W}$ and $11^{\circ} 23^{\prime}-13^{\circ} 7^{\prime} \mathrm{N}$, and its surface is about $34,000 \mathrm{~km}^{2}(12.6 \%$ of the national territory). The region is subdivided in 6 provinces namely Balé, Banwa, Kossi, Mouhoun, Nayala and Sourou. These provinces are divided in a total of 47 departments, themselves composed of 1061 villages (Ministère de l'Administration Territoriale et de la Décentralisation - Burkina Faso (MATD),2007). The climate of the region is of soudanosahelian type with the annual rainfall ranging between 500 to $1400 \mathrm{~mm}$ (MEDEV,2005). The region is drained by the Mouhoun river which is $280 \mathrm{~km}$ long. A dense hydrographic network made by permanent and temporary tributaries is woven around the Mouhoun river (figure 1).

\section{Parasitological survey}

\section{Sampling}

Among the 1061 villages of the 47 departments, one village was randomly selected from each department. To increase the chances to get a suitable environment for the block treatments for drug resistance testing i.e. where the risk of trypanosome infection is high enough, six additional villages were randomly selected from a list of 41 being located less than $5 \mathrm{~km}$ from the river or its main tributaries. Further random sampling of 50 cattle, 30 small ruminants and 10 donkeys was there organized. In total 2,650 cattle, 1,590 small ruminants and 530 donkeys were selected as theoretical sampling frame. For each sampled 
animal, information related to species, sex, age, breed, body condition score (BCS), livestock management system and history of trypanocidal treatments were recorded. The sampling took place in September and November 2007, i.e. during the transition rainy to dry season.

\section{Parasitological and serological analysis}

A blood sample was collected in heparinised Vacutainer ${ }^{\circledR}$ tubes from each animal by vein puncture of the jugular vein for the determination of the PCV and the detection of trypanosomes using the buffy-coat technique (Murray et al., 1977). The serum collected on dry Vacutainer ${ }^{\circledR}$ tubes was used for the detection of the anti-trypanosome antibodies. The dry tubes containing the blood of each animal were centrifuged ( $430 \mathrm{~g}, 10 \mathrm{~min}$ ) and sera were collected into Eppendorf ${ }^{\oplus}$ tubes that were kept at cool temperature on ice during the field operations and then at $-20^{\circ} \mathrm{C}$ before ELISA processing. The serological analyses were carried out using an indirect ELISA according to the protocol described by (Desquesnes et

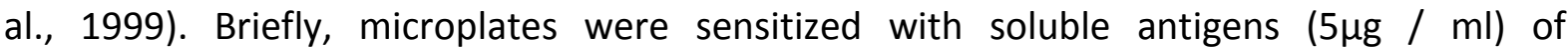
Trypanosoma vivax (IL1392), T. brucei (ILTat1.2), T. congolense savannah type (IL1180) or T. evansi. The results of the ELISA analyses were expressed as relative percentage positivity (RPP) compared to positive and negative reference samples. The positivity thresholds (PT) were fixed at $20 \%$ (Desquesnes et al. 1999).

\section{Statistical analysis}

Data from the different animal species were analysed separately in robust generalized linear models, using the villages as primary sampling units. Overall parasitological and serological prevalences were estimated from the 47 randomly selected villages (excluding the 6 additional villages closer to rivers) using logistic regressions without explanatory variables. All other analyses were performed on data originating from all 53 villages (including the 6 
additional villages closer to rivers), considering the distance to main rivers ( $>$ or $<=5 \mathrm{~km}$ ) as strata. Prevalences less than $5 \mathrm{~km}$ from main rivers and beyond were estimated using the distance to the rivers ( $>$ or $<=5 \mathrm{~km}$ ) as only binary explanatory variable. The significance of the distance to rivers and the animals' age on their serological status was evaluated in a multivariate model using these two parameters as continuous explanatory variables. Finally, the effect of trypanosome infections (observation of trypanosomes and seropositivity; explanatory variables) on the PCV and the BCS (responses) was evaluated in ordered multinomial logistic regressions. Body condition was classified as good, medium and bad whereas 3 PCV classes were created using $<20$ and $<26$ as cut-offs for the four animal species considered in this study. The proportion of animals and confidence interval were calculated for each class using a non-linear combination of estimators. A significance threshold of $5 \%$ was used in all statistical tests.

\section{RESULTS}

\section{Sampled animals}

A total of 2,002 cattle, 1,466 small ruminants, 481 donkeys were sampled from the 53 selected villages participating to the survey (table I). The sampled animals were mainly sedentary $(98.6 \%)$, with $64.3 \%$ of males, because of the presence of draught oxen. In the herds, $72.4 \%$ were Zebus (Bos indicus), $3.9 \%$ were taurines (Bos taurus) and $23.7 \%$ were crossbred. In sheep, the breed repartition was $80.2 \%, 5.4 \%$ and $14.4 \%$ for Djallonke, Bali-Bali and crossbreds respectively. Similarly, in goats, the proportion of Djallonke, Sahel and crossbred was $77.6 \%, 6.9 \%$ and $15.5 \%$ respectively.

The study showed that $11.7 \%$ and $12.9 \%$ of the cattle, for diminazene aceturate (DA) and isometamidium chloride (ISM) respectively, had received a treatment less than three 
months before the sampling; for sheep, those proportions were $5.25 \%$ and $0.2 \%$ for DA and ISM respectively. When considering goats and donkeys, the proportion of animals treated with DA was of $1.5 \%$ and $0 \%$ respectively, none was treated with ISM.

Isometamidium chloride (ISM) and diminazene aceturate (DA) were thus used in equal proportion in cattle whereas in small ruminants DA was used nearly exclusively. This result indicates that the use of trypanocides in small ruminants was much more curative than preventive, corroborating the low impact of trypanosomosis in these animals.

\section{Prevalence}

\section{Parasitological Prevalence (buffy coat)}

For the whole Region of the Boucle du Mouhoun, the parasitological prevalence of trypanosomosis was low. Indeed, in cattle, the most affected species, the mean prevalence was $0.77 \%$ (95\%C.I. $0.30-1.95 \%)$. In goats no case of infection was observed. Detailed results per species and per province are provided in table 2 .

Trypanosome infections were mainly due to $T$. vivax (75\%) with cases of $T$. congolense infections in cattle (25\%). No cases of infection by T. evansi was observed. The distance of the village from the river (more or less than $5 \mathrm{~km}$ ) had no significant effect on the parasitological status of the animals $(P=0.654)$. The $B C S$ were independent from the parasitological status of the animals $(P=0.642)$. However, the PCV values of parasitologically positive animals were significantly lower than the negative $(P<0.001)$. The proportion of cattle in the three PCV categories with their $95 \%$ C.I. are shown in table 3.

\section{Serological prevalence}

In cattle, the serological prevalence of trypanosomosis, for the entire Region of the Boucle du Mouhoun, was 34.2\% (95\%C.I. 26.1-43.4\%). For sheep, goats and donkeys, the 
prevalence were of $20.9 \%$ (95\%C.I. 12.2-33.5\%), 8.5\% (95\%C.I. 5.7-12.5\%) and 5.8\% (95\%C.I.

3.9-8.6\%) respectively. Detailed serological prevalences per species and per province are shown in table 4 . The distance of the village to the river had a significant effect $(P<0.001)$ on the serological prevalence of cattle with a $3 \%(95 \%$ C.I. $1.6-4.6 \%)$ reduction of the Odd Ratio per additional kilometre from the river. The same trend was observed for the small ruminants but not for the donkeys. As expected, the age of the cattle also influenced the serological status with a $10 \%$ (95\%C.I. $5.4-15.7 \%$ ) increase of the Odd Ratio per additional year of age. The same trend was observed for the other species. The BCS of the seropositives were not significantly different from the seronegatives $(P=0.066)$. The same trend was observed for the other species. The serological status was not correlated with the PCV values $(P=0.567)$. The same trend was observed in the other species.

\section{DISCUSSION}

This study highlighted (i) a low parasitological prevalence in all species, (ii) a high serological prevalence in cattle, (iii) a moderate serological prevalence in the other species, (iv) the efficient use of prophylactic and curative trypanocidal drugs in cattle and $(v)$ a parsimonious use of curative treatments in the other animal species.

About $25 \%$ of the cattle were treated $(12.9 \%$ with ISM and $11.7 \%$ with DA) against trypanosomosis less than 3 months before the survey while less than $3 \%$ and $0.5 \%$ of small ruminants and donkeys respectively had received a trypanocide treatment. The intensive use of trypanocidal drugs in cattle might be explained by the fact that herds reared in the Region of the Boucle du Mouhoun were composed from 96\% of trypanosomosis susceptible breed, mainly zebu and crossbred zebu / taurine. This is a common situation as the susceptible breeds are intuitively considered as generating more profit by the farmers because of their larger format despite the fact that they are equally productive (Maichomo 
et al., 2009). The restricted use of trypanocidal drugs in sheep might find its roots in the fact that the Djallonke is the most popular breed in the area as it presents a higher level of trypanotolerance compared to the local Bali-Bali breed and crossbreds (Agyemang,2005; Bengaly et al., 2001; Geerts et al., 2009). Goats were even less affected by the disease than sheep, which was expected, as this species is known to show an active defence against the tsetse flies by body movements and skin thrilling (Simukoko et al., 2007). The low rate of treatments in donkeys could be explained by the fact that ISM induces a local inflammatory reaction at the injection place (Eisler et al., 1996) and that the usual site of deep intramuscular injection corresponds to the place of harnessing which causes wounds handicapping draught donkeys for several days or weeks. Lastly, trypanosomosis prevalence in the various animal species seemed to reflect their systems of husbandry practice. Cattle and to a lesser extent sheep, which are generally led away from the village usually on the river edges in search of pasture, had the highest prevalence of trypanosomosis. On the contrary, goats and donkeys are generally kept around the village, away from the tsetse habitats e.g. in the dry season, donkeys are used for house works such as the transportation of water and building materials. Therefore, these two species presented less positive cases of trypanosomosis.

The study showed that $T$. vivax was the most prevalent trypanosome species $(75 \%, n=21)$ followed by $T$. congolense. This finding corroborates reports from previous surveys conducted in the Region of the Boucle du Mouhoun and other tsetse infested area in Burkina Faso (Bengaly et al. 2001; Bouyer and Bengaly ,2006; Desquesnes et al. 1999). The predominance of $T$. vivax might be explained by the exclusive presence in the study area of tsetse flies belonging to the palpalis group which is known as the effective vectors of this trypanosome species (Moloo and Kutuza ,1988) and also by the abundance of mechanical 
vectors also known to be effective transmitters of T. vivax (Desquesnes and Dia ,2003; Desquesnes and Dia ,2004).

As expected, haematocrits were consistently lower in seropositive animals (table 3). However, nearly $60 \%$ of those seropositives had a PCV higher than 26 and only around $5 \%$ with PCV values lower than 20 . This value of $26 \%$ constitutes a threshold that is a valuable indicator of trypanosomal infections when associated with the parasitological results (Marcotty et al., 2008). The low proportion of anaemic animals is a strong signal that treatments are effective in this area and that the health condition of the animals can be maintained even in the presence of the parasites and their vectors.

The low parasitological prevalences associated to high serological prevalences in cattle indicates that animals are frequently in contact with the parasites but are effectively cured by the trypanocidal drugs. The term of "cured" should be here considered as a persisting negative microscopical diagnosis after treatment. Diagnosis by PCR could certainly detect more positive animals but the question is then raised about the usefulness of diagnosing very low parasitaemia in healthy animals. In an experimental model, it was shown that some goats inoculated with T. vivax and treated either with DA or ISM developed very low and intermittent parasitaemia that were not affecting the weight and PCV's. All the goats presenting clinical signs were microscopically positive (Van den Bossche et al., 2010; Vitouley et al., 2012).

Interestingly, there was no correlation between the parasitological or serological status and the BCS. This brings even more weight on the efficacy of the drug treatment that are administered by the farmers. 
This study showed a strong correlation between the proximity to the river or main tributaries and the serological status of the cattle. In the dry season, the river edges still provide some pasture for livestock and the risk of trypanosome infection is high. Because of regular trypanocidal treatments, the parasitological prevalence remains low. In this study, prevalences were $0.77 \%$ and $34.2 \%$ for parasitology and serology respectively in cattle.

The parasitological prevalence (all animal species considered) in this study was far lower than what was found in previous surveys carried out in the same Region of the Boucle du Mouhoun. Indeed, Bouyer and Bengaly (2006) and Bengaly et al. (2001) found parasitological prevalence of $3.2 \%$ and $7.7 \%$ respectively as against $0.77 \%$ prevalence in this study. Those two previous studies were limited to the sole province of Mouhoun (not extended to the whole Region of the Boucle du Mouhoun), and were both carried out in the rainy season.

\section{Acknowledgements}

We would like to express our sincere thanks to the PATTEC coordinating team for financing this study. We are very grateful to Dr. Moussa Sylla and his team for the sample collection. We thank the Management and staff of CIRDES for their collaborative assistance in this survey. We appreciate and thank Dr Jérémy Bouyer for critically reading the manuscript. We do also appreciate the technical support of the PATTEC extension staff in the Region of the Boucle du Mouhoun for their immense contribution in field data collection. 


\section{Reference list}

Adam, Y., Marcotty, T., Cecchi, G., Mahama, C.I., Solano, P., Bengaly, Z., Van den Bossche, P., 2012. Bovine trypanosomosis in the Upper West Region of Ghana: Entomological, parasitological and serological cross-sectional surveys. Research in Veterinary Science 92, 462-468.

Agyemang, K., 2005. Trypanotolerant livestock in the context of trypanosomiasis intervention strategies. PAAT Technical Scientific Series 7, 1-66.

Bengaly, Z., Ganaba, R., Sidibe, I., Desquesnes, M., 2001. Trypanosomose animale chez les bovins dans la zone Sud-soudanienne du Burkina Faso. Revue d'Elevage et de Médecine vétérinaire des Pays tropicaux 54, 221-224.

Bouyer, J., Bengaly, Z., 2006. Evaluation de la situation entomologique et épidémiologique en vue de l'élaboration d'un plan de lutte contre les trypanosomoses animales et leur vecteur dans la zone d'intervention du PAEOB. Rapport d'expertise du Projet d'Appui aux Organisations d'Eleveurs de I'Ouest (PAEOB) - Bobo-Dioulasso 1-30.

Clausen, P.H., Sidibe, I., Kabore, I., Bauer, B., 1992. Development of multiple drug resistance of Trypanosoma congolense in zebu cattle under high natural tsetse fly challenge in the pastoral zone of Samorogouan, Burkina Faso. Acta Tropica 51, 229-236.

Desquesnes, M., Dia, M.L., 2003. Trypanosoma vivax: mechanical transmission in cattle by one of the most common African tabanids, Atylotus agrestis. Experimental Parasitology 103, 35-43.

Desquesnes, M., Dia, M.L., 2004. Mechanical transmission of Trypanosoma vivax in cattle by the African tabanid Atylotus fuscipes. Veterinary Parasitology 119, 9-19.

Desquesnes, M., Michel, J.F., de la Rocque, S., Solano, P., Millogo, L., Bengaly, Z., Sidibe, I., 1999. Enquête parasitologique et sérologique (Elisa-indirect) sur les trypanosomoses des bovins dans la zone de Sidéradougou, Burkina Faso. Revue d'Elevage et de Médecine vétérinaire des Pays tropicaux 52, 223-232.

Eisler, M.C., Elliott, C.T., Holmes, P.H., 1996. A simple competitive enzyme immunoassay for the detection of the trypanocidal drug isometamidium. Therapeutic Drug Monitoring 18, $73-$ 79.

Geerts, S., Osaer, S., Goossens, B., Faye, D., 2009. Trypanotolerance in small ruminants of sub-Saharan Africa. Trends in Parasitology 25, 132-138.

Hendrickx, G., Napala, A., Dao, B., Batawui, K., Bastiaensen, P., De Deken, R., Vermeilen, A., Vercruysse, J., Slingenbergh, J.H.W., 1999. The area-wide epidemiology of bovine trypanosomosis and its impact on mixed farming in subhumid West Africa; a case study in Togo. Veterinary Parasitology 84, 13-31. 
Kamuanga, M., Swallow, B.M., Sigue, H., Bauer, B., 2001. Evaluating contingent and actual contributions to a local public good: Tsetse control in the Yale agro-pastoral zone, Burkina Faso. Ecological Economics 39, 115-130.

Kone, N., N'Goran, E.K., Sidibe, I., Kombassere, A.W., Bouyer, J., 2011. Spatio-temporal distribution of tsetse and other biting flies in the Mouhoun River basin, Burkina Faso. Medical and Veterinary Entomology 25, 156-168.

Laveissière, C., 1976. Répartition des glossines en Haute Volta : effets de la grande sécheresse de 1972-1973. Cahiers ORSTOM, série Entomologie médicale et Parasitologie 14, 293-299.

Maichomo, M.W., Kosura, W.O., Gathuma, J.M., Gitau, G.K., Ndung'u, J.M., Nyamwaro, S.O., 2009. Economic assessment of the performance of trypanotolerant cattle breeds in a pastoral production system in Kenya. Journal of the South African Veterinary AssociationTydskrif Van Die Suid-Afrikaanse Veterinere Vereniging 80, 157-162.

Marcotty, T., Simukoko, H., Berkvens, D., Vercruysse, J., Praet, N., Van den Bossche, P., 2008. Evaluating the use of packed cell volume as an indicator of trypanosomal infections in cattle in eastern Zambia

2. Preventive Veterinary Medicine 87, 288-300.

McDermott, J.J., Woitag, T., Sidibe, I., Bauer, B., Diarra, B., Ouedraogo, D., Kamuanga, M., Peregrine, A.S., Eisler, M.C., Zessin, K.H., Mehlitz, D., Clausen, P.H., 2003. Field studies of drug-resistant cattle trypanosomes in Kenedougou Province, Burkina Faso. Acta Tropica 86, 93-103.

MEDEV, 2002. Lettre de Politique de Développement Rural Décentralisé. MEDEV (Ministère de l'Economie et du Développement du Burkina Faso)

http://www.dgatdlr.bf/download/lpdrd.pdf.,

MEDEV, 2004. Etude nationale prospective "Burkina 2025" : Rapport général. MEDEV (Ministère de l'Economie et du Développement du Burkina Faso) http://www.capdev.org/index.php?option=com phocadownload\&view=category\&downloa $\mathrm{d}=4: \mathrm{pp}-\mathrm{I}-2025 \& \mathrm{id}=2 \&$ Itemid=192,

MEDEV, 2005. Région de la Boucle du Mouhoun; Cadre stratégique Régional de Lutte contre la pauvreté, Ouagadougou, Burkina Faso. Rapport du Ministère de l'Economie et du Développement du Burkina Faso (MEDEV) 1-106.

Ministère de l'Administration Territoriale et de la Décentralisation - Burkina Faso (MATD), 2007. Liste des villages du Burkina Faso. Villages de la boucle du Mouhoun. http://www.matd.gov.bf/SiteMatd/documents/villagesbf1.pdf.

Ministère des Ressources Animales, 2006. Les statistiques du Secteur de l'Elevage au Burkina Faso. Rapport du Ministère des Ressources Animales du Burkina Faso 1-76. 
Ministère des Ressources Animales, 2010. Annuaire statistique. Annuaire statistique du secteur de l'élevage (Direction Générale de la Prévision et des Statistiques de I'Elevage) 1122.

Moloo, S.K., Kutuza, S.B., 1988. Comparative study on the infection rates of different laboratory strains of Glossina species by Trypanosoma congolense. Medical and Veterinary Entomology 2, 253-257.

Murray, M., Murray, P.K., Mcintyre, W.I.M., 1977. Improved parasitological technique for diagnosis of African trypanosomiasis. Transactions of the Royal Society of Tropical Medicine and Hygiene 71, 325-326.

Simukoko, H., Marcotty, T., Phiri, I., Geysen, D., Vercruysse, J., Van den Bossche, P., 2007. The comparative role of cattle, goats and pigs in the epidemiology of livestock trypanosomiasis on the plateau of eastern Zambia. Veterinary Parasitology 147, 231-238.

Solano, P., Ravel, S., de, M.T., 2010. How can tsetse population genetics contribute to African trypanosomiasis control? Trends Parasitol. 26, 255-263.

Sow, A., Bengaly, Z., Bouyer, J., Bauer, B., Van den Bossche, P., 2010. Fifty years of research and fight against tsetse flies and animal trypanosomosis in Burkina Faso. An overview. Bulletin of Animal Health and Production in Africa 58, 95-118.

Sow, A., Sidibe, I., Bengaly, Z., Marcotty, T., Séré, M., Diallo, A., Vitouley, H.S., Ouédraogo, M., Akoda, K., Van den Bossche, P., Van den Abbeele, J., De Deken, R., Delespaux, V., 2012. Field detection of resistance to isometamidium chloride and diminazene aceturate in Trypanosoma vivax from the Region of the Boucle du Mouhoun in Burkina Faso. Veterinary Parasitology 187, 105-111.

Talaki, E., Diall, O., Sidibe, I., Belem, A.M.G., Pangui, L.J., 2007. Méthode de diagnostic rapide de la chimiorésistance des trypanocides à l'isométamidium et au diminazène sur le terrain. Revue Africaine de Santé et de Productions Animales (RASPA) 29-36.

Van den Bossche, P., de la Rocque, S., Hendrickx, G., Bouyer, J., 2010. A changing environment and the epidemiology of tsetse-transmitted livestock trypanosomiasis. Trends in Parasitology 26, 236-243.

Vitouley, H.S., Sidibe, I., Bengaly, Z., Marcotty, T., Van den Abbeele, J., Delespaux, V., 2012. Is trypanocidal drug resistance a threat for livestock health and production in endemic areas? Food for thoughts from Sahelian goats infected by Trypanosoma vivax in Bobo Dioulasso (Burkina Faso). Veterinary Parasitology 187, 105-111-DOI information: 10.1016/j.vetpar.2011.12.019. 
Table 1. Number of sampled animals per province in the Region of the Boucle du Mouhoun

\begin{tabular}{|l|c|c|c|c|c|c|c|}
\hline & & \multicolumn{6}{|c}{ Number of sampled animals } \\
\cline { 3 - 8 } Province & Number of villages & Cattle & Sheep & Goats & Donkeys & Horses & Camel \\
\hline Balé & 11 & 428 & 268 & 45 & 101 & 0 & 0 \\
\hline Banwa & 7 & 245 & 114 & 36 & 59 & 1 & 0 \\
\hline Kossi & 12 & 508 & 226 & 126 & 114 & 3 & 0 \\
\hline Mouhoun & 9 & 315 & 172 & 73 & 72 & 0 & 0 \\
\hline Nayala & 6 & 279 & 88 & 88 & 60 & 0 & 0 \\
\hline Sourou & 8 & 227 & 141 & 89 & 75 & 0 & 1 \\
\hline Total & 53 & 2002 & 1009 & 457 & 481 & 4 & 1 \\
\hline
\end{tabular}


Table 2. Parasitological prevalence of trypanosomosis by province (September to November)

\begin{tabular}{|l|l|l|l|l|l|l|l|l|l|}
\hline Province & Cattle & $(\mathbf{n = 2 0 0 2})$ & & Sheep & $(\mathbf{n = 1 0 0 9})$ & & Donkeys & $(\mathbf{n = 4 8 1})$ \\
\hline & $\mathrm{P}(\%)$ & $<$ & $>$ & $\mathrm{P}(\%)$ & $<$ & $>$ & $\mathrm{P}(\%)$ & $<$ & $>$ \\
\hline Balé & 0,7 & 0,4 & 1,2 & 0,4 & 0,2 & 1,1 & 2,0 & 1,1 & 3,7 \\
\hline Banwa & 2,0 & 1,5 & 2,7 & 0,9 & 0,5 & 1,7 & 1,7 & 0,9 & 3,3 \\
\hline Kossi & 0,8 & 0,5 & 1,3 & 0,9 & 0,5 & 1,7 & 0,0 & nd & nd \\
\hline Mouhoun & 1,9 & 1,4 & 2,6 & 0,0 & nd & nd & 1,4 & 0,7 & 2,9 \\
\hline Nayala & 2,2 & 1,6 & 2,9 & 1,1 & 0,6 & 2,0 & 0,0 & nd & nd \\
\hline Sourou & 0,9 & 0,6 & 1,4 & 0,0 & nd & nd & 0,0 & nd & nd \\
\hline
\end{tabular}

With P as prevalence; < lower limit confidence interval; > upper limit confidence interval 
Table 3. Proportion of cattle in the 3 PCV categories

$$
\begin{array}{|l|l|l|}
\hline \text { pcv }>26 \% & 20 \%<\text { pcv }<26 \% & \text { pcv }<20 \% \\
\hline
\end{array}
$$

\begin{tabular}{llll}
\hline Seronegative $86.0 \%(83.0-89.1)$ & $12.7 \%(9.9-15.6)$ & $1.2 \%(0.7-1.7)$
\end{tabular}

\begin{tabular}{l|l|l|l} 
Seropositive & $58.5 \%(40.3-76.6)$ & $36.5 \%(21.4-51.5)$ & $5,1 \%(1.4-8.8)$ \\
\hline
\end{tabular}

Between brackets the $95 \%$ C.I. 
Table 4. Serological prevalence of trypanosomosis by province (September to November)

\begin{tabular}{|c|c|c|c|c|c|c|c|c|c|c|c|c|}
\hline Province & Cattle & $(n=2002)$ & & Sheep & $(n=1009)$ & & Goats & $(n=457)$ & & Donkeys & $(n=481)$ & \\
\hline & $\mathrm{P}(\%)$ & $<$ & $>$ & $\mathrm{P}(\%)$ & $<$ & $>$ & $\mathrm{P}(\%)$ & $<$ & $>$ & $\mathrm{P}(\%)$ & $<$ & $>$ \\
\hline Balé & 68,9 & 66,8 & 70,9 & 51,1 & 48,0 & 54,2 & 26,7 & 22,8 & 30,9 & 5,9 & 4,1 & 8,4 \\
\hline Banwa & 37,1 & 35,0 & 39,2 & 15,8 & 13,7 & 18,2 & 11,1 & 8,5 & 14,3 & 17,0 & 13,9 & 20,6 \\
\hline Kossi & 19,3 & 17,6 & 21,1 & 6,2 & 4,9 & 7,9 & 10,3 & 7,8 & 13,4 & 10,5 & 8,1 & 13,6 \\
\hline Mouhoun & 45,7 & 43,5 & 47,9 & 13,4 & 11,4 & 15,6 & 5,5 & 3,7 & 8,0 & 2,8 & 1,6 & 4,7 \\
\hline Nayala & 27,2 & 25,3 & 29,2 & 3,4 & 2,4 & 4,7 & 1,1 & 0,5 & 2,6 & 15,0 & 12,1 & 18,5 \\
\hline Sourou & 19,8 & 18,1 & 21,6 & 5,0 & 3,8 & 6,5 & 10,1 & 7,7 & 13,2 & 6,7 & 4,8 & 9,3 \\
\hline
\end{tabular}

With $\mathrm{P}$ as prevalence; < lower limit confidence interval; > upper limit confidence interval 


\section{List of figures}

Figure 1. Serological prevalence of bovine trypanosomosis in the region of the Boucle du Mouhoun

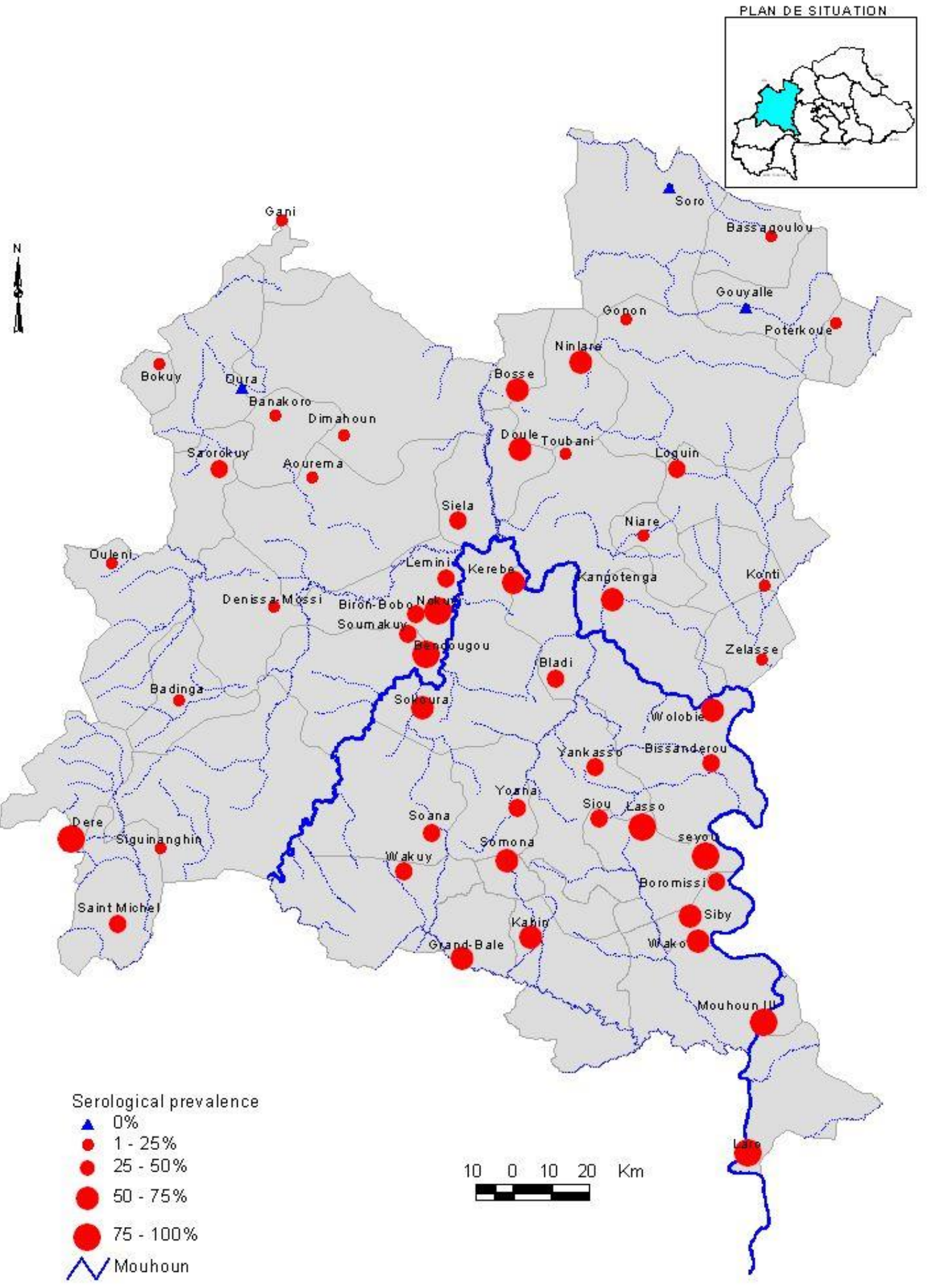

